\title{
Prevalence, Parents' Hesitancy, and Determinants of COVID-19 Vaccination Among Children: A Multi- Country Study From the Eastern Mediterranean Region
}

\section{Moawiah Khatatbeh ( $\sim$ Moawia.m@yu.edu.jo)}

Department of Basic Medical Sciences, Faculty of Medicine, Yarmouk University, Irbid, Jordan.

\section{Samir Albalas}

Department of Health Services Administration, Yarmouk University, Irbid, Jordan.

Haitham Khatatbeh

Doctoral School of Health Sciences, Faculty of Health Sciences, University of Pécs, Pécs, Hungary.

\section{Waleed Momani}

Department of Basic Medical Sciences, Faculty of Medicine, Yarmouk University, Irbid, Jordan.

\section{Omar Melhem}

Department of Nursing, Fatima College of Health Sciences, Abu Dhabi, United Arab Emirates.

\section{Omar Al Omari}

College of Nursing, Sultan Qaboos University, Muscat, Oman.

\section{Zeinab Tarhini}

Institute of Epidemiology and Tropical Neurology, GEIST, Limoges, France.

\section{Ashraf A'aqoulah}

Department of Health Systems Management, College of Public Health and Health Informatics, King Saud Bin Abdulaziz University for Health Sciences, Riyadh, Saudi Arabia.

\section{Mohammed Al-Jubouri}

College of Nursing, University of Baghdad, Iraq.

\section{Abdulqadir J. Nashwan}

Hamad Medical Corporation, Doha, Qatar.

\section{Ghaleb Adwan}

Department of Biology and Biotechnology, An-Najah National University, Nablus, Palestine.

\section{Zaid Altaany}

Department of Basic Medical Sciences, Faculty of Medicine, Yarmouk University, Irbid, Jordan.

\section{Ayat Nashwan}

Department of Sociology and Social Work, Yarmouk University, Irbid, Jordan.

\section{Khaled Al-Waqfi}

Department of Basic Medical Sciences, Faculty of Medicine, Yarmouk University, Irbid, Jordan.

\section{Lujain Abuirsheid}


Department of Basic Medical Sciences, Faculty of Medicine, Yarmouk University, Irbid, Jordan.

Raghad Ayasreh

Department of Basic Medical Sciences, Faculty of Medicine, Yarmouk University, Irbid, Jordan.

Mohammed Al Mutairi

Ministry of Health, Kuwait.

\section{Ala'a B. Al-Tammemi}

Department of Family and Occupational Medicine, Faculty of Medicine, University of Debrecen, Debrecen, Hungary.

\section{Research Article}

Keywords: Arab countries, attitude, COVID-19, hesitancy, prevalence, vaccination, EMR

Posted Date: February 1st, 2022

DOI: https://doi.org/10.21203/rs.3.rs-1280929/v1

License: (c) (1) This work is licensed under a Creative Commons Attribution 4.0 International License. Read Full License 


\section{Abstract}

Background: Huge efforts are being made to control the spread and impacts of the coronavirus pandemic using vaccines. However, willingness to be vaccinated depends on factors beyond the availability of vaccines. The aim of this study was three-folded: to assess the prevalence of children's vaccination against COVID-19, to explore parents' attitudes towards children's vaccination, and to discover the factors associated with parents' hesitancy towards children's vaccination in several countries in the Eastern Mediterranean Region (EMR).

Methods: This study utilized a cross-sectional descriptive design. A sample of 3744 parents from eight countries, namely, Iraq, Jordan, Kuwait, Lebanon, Palestine, Qatar, Saudi Arabia (KSA), and the United Arab Emirates (UAE), was conveniently approached and surveyed using Google forms. The participants have responded to a 42-item questionnaire pertaining to socio-demographics, children vaccination status, knowledge about COVID-19 vaccines, and attitudes towards vaccinating children and the vaccine itself.

Results: The prevalence of vaccinated children against COVID-19 was $32 \%$ as indicated by the parents. Concerning parents' attitudes towards vaccines safety, about one third of participants (32.5\%) believe that all vaccines are not safe. In the regression analysis, children's vaccination was significantly correlated with parents' age, education, occupation, parents' previous COVID-19 infection, and their vaccination status. Participants aged $\geq 50$ years and those aged $40-50$ years had an odds ratio of 17.9 $(\mathrm{OR}=17.9, \mathrm{Cl}: 11.16-28.97)$ and $13.2(\mathrm{OR}=13.2$, Cl: 8.42-20.88); respectively, for vaccinating their children compared to those aged 18-29 years. Parents who had COVID-19 vaccine were about five folds more likely to vaccinate their children compared with parents who did not receive the vaccine $(\mathrm{OR}=4.9, \mathrm{Cl}$ : 3.127.70). The prevalence of children's vaccination in the participating Arab countries is still not promising.

Conclusion: To encourage parents, vaccinate their children against COVID-19, Arab governments should strategize accordingly. Reassurance of the efficacy and effectiveness of the vaccine should target the general population using educational campaigns, social media, and official TV and radio channels.

\section{Background}

The Coronavirus Disease-2019 (COVID-19) was announced as a Public Health Emergency of International Concern (PHEIC) in January 2020, with 5.5 million deaths reported until January 2022 [1]. Most countries, around the World, have witnessed large numbers of cases despite the precautions taken [2], leading to severe impact including psychological burden [3, 4]. Efficacious vaccine is an essential tool in the fight against the current COVID-19 pandemic to achieve collective immunity, which can help reduce transmission, hospitalizations, and intensive care utilization, as well as prevent additional mortality [5].

Several COVID-19 vaccines are now available for public. However, major issues have been identified to affect vaccine coverage, including limited manufacturing capacity, global inequality in the distribution of COVID-19 vaccines, and most importantly vaccine hesitancy which could represent a major challenge in 
the global efforts to control the pandemic [6, 7]. Vaccine hesitancy refers to a delay in accepting or refusing vaccination despite its availability [8].

Many studies around the world have reported vaccine hesitancy among the public and this was reflected in a systematic review involved 31 published studies [9]. One-third of participants in a study from four African and Middle Eastern countries were hesitant about getting vaccinated against the COVID-19 [10]. Similar results were reported from Bangladesh, India, Pakistan, Nepal [11], and Japan [12]. Arab countries also reported similar trends [13-15].Certainly, individuals who are hesitant in getting vaccinated query the usefulness and safety of vaccines for their children [16]. In Italy, a cross-sectional study was conducted to evaluate the knowledge, attitude, and intention to vaccinate children $<18$ years. They found that $41.2 \%$ of families of children $\geq 12$ years and $36.1 \%$ among families of children $<12$ years would not vaccinate their children [16]. Perceived vaccine safety and efficacy and perceived risk of transmission of infection to adults were the two determinants of intention to vaccinate for both age groups [16].

Many factors influence vaccination decisions, including trust in the government and health care professionals, social influences, high levels of knowledge about the vaccine, and general positive attitudes toward vaccines [17]. Another study found that parents with different levels of education and employment status had significant differences in vaccine knowledge and awareness; similarly, these two factors also significantly influenced parental vaccine hesitancy. The knowledge score of parents was inversely correlated with vaccine hesitancy and moderately associated with their awareness score [18].

In a study conducted in Poland regarding children vaccination, the main concerns expressed by parents were the possibility of adverse effects, the lack of adequate testing of the preparations in children, and the fear of future complications [19]. Therefore, the COVID-19 vaccine must have proven safety and efficacy in preventing complications as well as transmission to ensure vaccination of children [20].

In the Arab countries, like Jordan, commitment to precaution measures against COVID-19 virus such as hand washing, wearing a face mask, and social distancing is not optimal [21]. This was evident from a previous study which found that contaminated hands can act as carriers for different infectious microbes [22]. Though, figures of the vaccinated population against COVID-19 in Arab countries, including children, are still not promising. To our knowledge, no studies have been conducted in these countries to assess the attitudes of parents towards children vaccination against COVID-19 infection. The aims of this study were to (1) assess the prevalence of children's vaccination against COVID-19, (2) assess parents' attitudes toward children's vaccination, and (3) study factors associated with vaccination's status and hesitancy of parents towards children's vaccination in several Arab countries.

\section{Methods And Materials}

\subsection{Study Setting, Design, and Participants}

Our study was conducted in eight countries located in the Eastern Mediterranean Region (EMR), namely: Iraq, Jordan, Kuwait, Lebanon, Palestine, Qatar, Saudi Arabia (KSA), and the United Arab Emirates (UAE). 
A descriptive questionnaire-based cross-sectional online survey was employed in this study focusing on married individuals having children (parents). A convenience sample was approached through social media platforms. A questionnaire was firstly developed in English, then it was translated into Arabic (the native language of our respondents) by two bilingual specialists. The questionnaire was then uploaded to Google Form ${ }^{\circledR}$ and disseminated to those who could access the online survey. The inclusion criteria included being a citizen of any participating country, aged 18 or older, married and having children, reading, and understanding Arabic, and being willing to fill the online questionnaire. The google form led participants who were single or not having children to submit their responses at early stage and their responses were excluded. An online link of the questionnaire, along with an introductory letter about the study, was sent to participants via media platforms like Facebook ${ }^{\circledR}$, WhatsApp ${ }^{\circledR}$, Twitter ${ }^{\circledR}$, and email addresses, for a period of four weeks; 15-November- 13-December 2021. In addition, respondents were asked to share the questionnaire link with their relatives, friends, and social networks.

\subsection{Study Instrument}

The authors have reviewed the available literature and developed a 42-item questionnaire composed of three main sections. The first section consisted of 12 questions on participants' socio-demographic characteristics such as age, gender, marital status, having children, education, nature of work or study, and country of residence. The second section comprised four questions that solicited general knowledge about the COVID-19 vaccine. The third section of the questionnaire consisted of 26 items and inquired about participants' attitudes towards COVID-19 vaccination of their children and the vaccine itself.

\subsection{Validity and Reliability}

Two researchers checked the content of the questionnaire and its face validity before the final approval. To ensure its reliability, the questionnaire was pilot tested with the first 40 responses. Based on these responses and the feedback, refinements were made. The Cronbach's alpha score was found to be 0.81 . The responses of the pilot-testing were excluded from the final analysis.

\subsection{Ethical Considerations}

All participants have given their informed consent through reading the following statement and ticking a box next to it: "Completing the questionnaire would be considered consent to voluntary participation". Participants were informed that the study would not disclose any personal information and that their data would be stored under high-security settings with only the research team having access to these data.

\subsection{Statistical Analysis}

The Statistical Package for Social Sciences (SPSS- IBM, Chicago, IL, USA) was used to analyze the data. Categorical variables were reported as frequency counts and percentages. A cross-tabulation analysis using the chi-square test was employed to assess significant differences between categorical variables. Finally, all statistically significant factors revealed from the cross-tabulation analysis were subjected to a 
backward Wald stepwise binary logistic regression analysis to assess the independent effect of each factor after controlling for potential confounders. A P value $<0.05$ was set for statistical significance.

\section{Results}

A total of 3744 participants with valid responses were involved in the final analysis. More than half of the sample $(55.5 \%)$ was females $(n=2078)$ and $44.5 \%(n=1666)$ was males. Interestingly, about $40 \%$ of the study population have been diagnosed with COVID-19 infection and the majority ( $83 \%, n=3108)$ have been vaccinated against the infection. The socio-demographic characteristics of the study population are shown in Table 1. 
Table 1

Socio-Demographic Characteristics of the Study Participants $(\mathrm{N}=3744)$

\begin{tabular}{|ll|}
\hline Characteristic & $\mathbf{n}(\%)$ \\
\hline Gender & $1666(44.5)$ \\
\hline Fale & $2078(55.5)$ \\
\hline Age (years) & \\
\hline $18-29$ & $331(8.8)$ \\
\hline $30-39$ & $1561(41.7)$ \\
\hline $40-49$ & $1340(35.8)$ \\
\hline$>50$ & $512(13.7)$ \\
\hline Work or study field & \\
\hline None health-related & $2679(71.6)$ \\
\hline Health-related & $1065(28.4)$ \\
\hline Education & \\
\hline Secondary or less & $544(14.5)$ \\
\hline$\geq$ Graduate & $3200(85.5)$ \\
\hline Received a CoVID-19 vaccine & \\
\hline No & $256(6.8)$ \\
\hline Yes & $3108(83.0)$ \\
\hline I intend to get the vaccine & $173(4.6)$ \\
\hline I do not intend to get the vaccine & $207(5.5)$ \\
\hline Country of Residence & \\
\hline Jordan & $424(11.3)$ \\
\hline KSA & $997(26.6)$ \\
\hline UAE & \\
\hline Kuwait & $(11.3)$ \\
\hline Lebanon & \\
\hline Palestine & \\
\hline
\end{tabular}




\begin{tabular}{|ll|}
\hline Characteristic & $\mathbf{n}(\%)$ \\
\hline Qatar & $306(8.2)$ \\
\hline Iraq & $368(9.8)$ \\
\hline Previous Diagnosis of COVID-19 & \\
\hline No & $2223(59.4)$ \\
\hline Yes & $1521(40.6)$ \\
\hline
\end{tabular}

Table 2 shows the number of children, their age, and beliefs of the study population towards the COVID19 vaccine for children. About one-third of the sample (32.5\%) reported that all COVID-19 vaccines are not safe and close percentage reported that their children received the vaccine $(31.9 \%, n=1194)$. Figure 1 shows children's vaccination prevalence per country and figure 2 shows the overall prevalence of children's vaccination in eight Arab countries. 
Table 2

Number of children, their age, and beliefs of parents towards COVID-19 vaccine for the children ( $N=$ 3744)

\begin{tabular}{|c|c|}
\hline Characteristic & $\mathrm{n}(\%)$ \\
\hline \multicolumn{2}{|l|}{ Number of children } \\
\hline 1 & $578(15.4)$ \\
\hline 2 & $\begin{array}{l}1022 \\
(27.3)\end{array}$ \\
\hline$\geq 3$ & $\begin{array}{l}2144 \\
(57.3)\end{array}$ \\
\hline \multicolumn{2}{|l|}{ Age of children/year } \\
\hline All kids are younger than 12 & $\begin{array}{l}1817 \\
(48.5)\end{array}$ \\
\hline All kids between 12-17 & $579(15.5)$ \\
\hline I have kids in both above categories & $\begin{array}{l}1348 \\
(36.0)\end{array}$ \\
\hline \multicolumn{2}{|c|}{ If any of your kids had COVID-19 vaccine } \\
\hline No & $\begin{array}{l}2550 \\
(68.1)\end{array}$ \\
\hline Yes & $\begin{array}{l}1194 \\
(31.9)\end{array}$ \\
\hline \multicolumn{2}{|c|}{$\begin{array}{l}\text { Will the freedom to choose the type of vaccine affect your decision to vaccinate your } \\
\text { children? }\end{array}$} \\
\hline No & $\begin{array}{l}1211 \\
(32.3)\end{array}$ \\
\hline Yes & $\begin{array}{l}1361 \\
(36.4)\end{array}$ \\
\hline Maybe & $\begin{array}{l}1172 \\
(31.3)\end{array}$ \\
\hline \multicolumn{2}{|c|}{ In your opinion, are COVID-19 vaccines safe? } \\
\hline All vaccines are safe & $\begin{array}{l}2527 \\
(67.5)\end{array}$ \\
\hline All vaccines are not safe & $\begin{array}{l}1217 \\
(32.5)\end{array}$ \\
\hline
\end{tabular}

To assess the impact of socio-demographic characteristics on the vaccination against COVID-19 among children, a cross-tabulation analysis was performed and revealed that all these factors were significantly 
correlated with children's vaccination status $(p \leq 0.05)$. Interestingly, parents whose work or study was health-related showed a higher tendency for not vaccinating their children compared to others. Moreover, willingness to vaccinate increased with an increased parents' age. Remarkably, less than $4 \%$ of parents whose children were younger than 12 years have vaccinated their children. The results of this analysis are shown in Table 3. 
Table 3

Cross-tabulation of socio-demographic factors associated with COVID-19 vaccination among children $(\mathrm{N}=3744)$

\begin{tabular}{|c|c|c|c|}
\hline \multirow[t]{2}{*}{ Variable } & \multicolumn{2}{|c|}{ Children vaccination status } & \multirow[t]{2}{*}{$P$ value } \\
\hline & No (\%) & Yes (\%) & \\
\hline Gender & & & 0.037 \\
\hline Male & $1105(66.3)$ & $561(33.7)$ & \\
\hline Female & $1445(69.5)$ & $633(30.5)$ & \\
\hline Participant's education & & & $<0.001$ \\
\hline Secondary or less & $311(57.2)$ & $233(42.8)$ & \\
\hline$\geq$ Graduate & $2239(70.0)$ & $961(30.0)$ & \\
\hline Work or study field & & & $<0.001$ \\
\hline None health-related & $1770(66.1)$ & 909 (33.9) & \\
\hline Health-related & $780(73.2)$ & $285(26.8)$ & \\
\hline Participant's age/year & & & $<0.001$ \\
\hline $18-29$ & $309(93.4)$ & $22(6.6)$ & \\
\hline $30-39$ & 1335 (85.5) & $226(14.5)$ & \\
\hline $40-40$ & $690(51.5)$ & $650(48.5)$ & \\
\hline$\geq 50$ & $216(42.2)$ & $296(57.8)$ & \\
\hline Number of children & & & $<0.001$ \\
\hline 1 & $458(79.2)$ & $120(20.8)$ & \\
\hline 2 & 837 (81.9) & $185(18.1)$ & \\
\hline$\geq 3$ & $1255(58.5)$ & $889(41.5)$ & \\
\hline Children age & & & $<0.001$ \\
\hline All kids are younger than 12 & $1747(96.1)$ & $70(3.9)$ & \\
\hline All kids are between 12-17 & $254(43.9)$ & $325(56.1)$ & \\
\hline I have kids in both above categories & 549 (40.7) & 799 (59.3) & \\
\hline If the parent had COVID-19 before & & & $<0.001$ \\
\hline No & $1462(65.8)$ & $761(34.2)$ & \\
\hline Yes & $1088(71.5)$ & $433(28.5)$ & \\
\hline
\end{tabular}




\begin{tabular}{|c|c|c|c|}
\hline \multirow[t]{2}{*}{ Variable } & \multicolumn{2}{|c|}{ Children vaccination status } & \multirow[t]{2}{*}{$P$ value } \\
\hline & No (\%) & Yes (\%) & \\
\hline If the parent had COVID-19 vaccine & & & $<0.001$ \\
\hline No & $231(90.2)$ & $25(9.8)$ & \\
\hline Yes & $2011(64.7)$ & $1097(35.3)$ & \\
\hline I intend to get the vaccine & $134(77.5)$ & $39(22.5)$ & \\
\hline I do not intend to get the vaccine & $174(84.1)$ & $33(15.9)$ & \\
\hline
\end{tabular}

As seen in Table 3, parents who have been vaccinated against COVID-19 and those who intend to get the vaccine in the future were more likely to have vaccinated children. With respect to the country of residence and perceived necessity for COVID-19 vaccine with vaccination status among children, parents living in KSA, UAE, Kuwait, and Iraq were more willing to vaccinate their children compared to parents from Jordan, Lebanon, Palestine, and Qatar. Furthermore, parents who believed that the vaccine is necessary for individuals younger than 18 years were more willing to vaccinate their children than those who didn't have the same belief. Table 4 illustrates these associations. 
Table 4

Cross-tabulation of vaccine related factors and country of residence with COVID-19 vaccination among children $(n=3744)$

\begin{tabular}{|c|c|c|c|}
\hline \multirow[t]{2}{*}{ Variable } & \multicolumn{2}{|c|}{ Children vaccination status } & \multirow[t]{2}{*}{$P$ value } \\
\hline & No (\%) & Yes (\%) & \\
\hline \multicolumn{3}{|l|}{ Country of residence } & $<0.001$ \\
\hline Jordan & $817(81.9)$ & $180(18.1)$ & \\
\hline KSA & $213(50.8)$ & $206(49.2)$ & \\
\hline UAE & $170(51.1)$ & $163(48.9)$ & \\
\hline Kuwait & $242(50.9)$ & $233(49.1)$ & \\
\hline Lebanon & $348(82.1)$ & $76(17.9)$ & \\
\hline Palestine & $330(78.2)$ & $92(21.8)$ & \\
\hline Qatar & $234(76.5)$ & $72(23.5)$ & \\
\hline Iraq & $196(53.3)$ & $172(46.7)$ & \\
\hline \multicolumn{3}{|c|}{ I advise other parents to vaccinate their children against COVID-19 } & $<0.001$ \\
\hline No & $1020(83.6)$ & $200(16.4)$ & \\
\hline Yes & $706(48.6)$ & $747(51.4)$ & \\
\hline Neutral & $824(76.9)$ & $247(23.1)$ & \\
\hline \multicolumn{3}{|c|}{ COVID-19 vaccine is necessary for those younger than 18 years } & $<0.001$ \\
\hline No & $1318(81.1)$ & $308(18.9)$ & \\
\hline Yes & $654(49.8)$ & 659 (50.2) & \\
\hline
\end{tabular}

Table 5 presents parents' attitudes towards COVID-19 vaccine and children's vaccination status. Amazingly, all attitudes' items had significant statistical associations with vaccination status $(p \leq 0.05)$. About half of parents who believed that COVID-19 vaccines are safe for children had vaccinated their offspring compared to only about $20 \%$ of parents who did not have the same belief. In addition, parents who were against children's vaccines due to the unknown long-term side effects of the vaccine or perceived a lack of scientific research about the effects of the vaccine on children were less likely to vaccinate their children. Most importantly, willingness to vaccinate children decreased among parents who think that the vaccine may change human genes. 
Table 5

Parents' attitudes towards COVID-19 vaccination of children and children vaccination status $(n=3744)$ Variable Children vaccination status Total (n)

No (\%) Yes (\%)

$\mathrm{P}$ value

COVID-19 vaccine protects children from the infection

$<$

0.001

$\begin{array}{llll}\text { No } & 1092(81.0) & 256(19.0) & 1348 \\ \text { Yes } & 646(51.7) & 633(48.3) & 1249 \\ \text { Neutral } & 812(70.8) & 335(29.2) & 1147\end{array}$

COVID-19 vaccines are safe to be used on children

$<$

0.001

No

$1115(80.4)$

$271(19.6)$

1386

Yes

$468(50.2)$

$465(49.8)$

933

Neutral

$967(67.9)$

$458(32.1)$

1425

I encourage vaccination of children against COVID-19

$<$

0.001

$\begin{array}{llll}\text { No } & 1225(80.9) & 290(19.1) & 1515 \\ \text { Yes } & 647(52.0) & 598(48.0) & 1245 \\ \text { Neutral } & 678(68.9) & 306(31.1) & 948\end{array}$

A child can be infected with COVID-19 even after vaccination

$<$

0.001

$\begin{array}{llll}\text { No } & 122(68.5) & 56(31.5) & 178 \\ \text { Yes } & 1957(69.6) & 856(30.4) & 2813 \\ \text { Neutral } & 471(62.5) & 282(37.5) & 753\end{array}$

A child who had COVID-19 infection do not need the vaccine

$<$

0.001

No

$646(58.4)$

$460(41.6)$

1106

Yes

$1017(74.9)$

$341(25.1)$

1358

Neutral

$887(69.3)$

$393(30.7)$

1280

Natural immunity of the infection is better than vaccination

$\begin{array}{llll}\text { No } & 450(56.2) & 351(43.8) & 801 \\ \text { Yes } & 1539(76.0) & 487(24.0) & 2026\end{array}$




\begin{tabular}{|c|c|c|c|c|}
\hline \multirow[t]{2}{*}{ Variable } & \multicolumn{2}{|c|}{ Children vaccination status } & \multirow[t]{2}{*}{ Total (n) } & \multirow{2}{*}{$\begin{array}{l}\mathrm{P} \\
\text { value }\end{array}$} \\
\hline & No (\%) & Yes (\%) & & \\
\hline Neutral & $561(61.2)$ & $356(38.8)$ & 917 & \\
\hline \multicolumn{4}{|c|}{ A healthy child does not require COVID-19 vaccine } & $\begin{array}{l}< \\
0.001\end{array}$ \\
\hline No & $672(57.5)$ & $496(42.5)$ & 1168 & \\
\hline Yes & $1250(76.0)$ & $395(24.0)$ & 1645 & \\
\hline Neutral & $628(67.5)$ & $303(32.5)$ & 931 & \\
\hline \multicolumn{4}{|c|}{ COVID-19 is not serious and does not require a vaccine } & $\begin{array}{l}< \\
0.001\end{array}$ \\
\hline No & $1115(60.6)$ & $725(39.4)$ & 1840 & \\
\hline Yes & $606(77.5)$ & $176(22.5)$ & 782 & \\
\hline Neutral & $829(73.9)$ & $293(26.1)$ & 1122 & \\
\hline \multicolumn{4}{|c|}{ Face masks, social distancing, and sterilization are enough to prevent spread of COVID-19 } & $\begin{array}{l}< \\
0.001\end{array}$ \\
\hline No & $644(61.9)$ & $397(38.1)$ & 1041 & \\
\hline Yes & $1384(72.1)$ & $535(27.9)$ & 1919 & \\
\hline Neutral & $522(66.6)$ & $262(33.4)$ & 784 & \\
\hline \multicolumn{4}{|c|}{ I'm against all children vaccines, not only the COVID-19 vaccine } & $\begin{array}{l}< \\
0.001\end{array}$ \\
\hline No & $1582(65.0)$ & $852(35.0)$ & 2434 & \\
\hline Yes & $466(77.8)$ & $133(22.2)$ & 599 & \\
\hline Neutral & $502(70.6)$ & $209(29.4)$ & 711 & \\
\hline \multicolumn{4}{|c|}{ COVID-19 vaccine should only be given to elderly and children with diseases } & $\begin{array}{l}< \\
0.001\end{array}$ \\
\hline No & $943(59.9)$ & $631(40.1)$ & 1574 & \\
\hline Yes & $841(74.2)$ & $293(25.8)$ & 1134 & \\
\hline Neutral & $766(73.9)$ & $270(26.1)$ & 1036 & \\
\hline \multicolumn{4}{|c|}{ The benefit of COVID-19 vaccine outweighs its side effects } & $\hat{L}_{0.001}$ \\
\hline No & $757(81.0)$ & $178(19.0)$ & 935 & \\
\hline Yes & 805 (58.2) & $577(41.8)$ & 1382 & \\
\hline
\end{tabular}




\begin{tabular}{|c|c|c|c|c|}
\hline \multirow[t]{2}{*}{ Variable } & \multicolumn{2}{|c|}{ Children vaccination status } & \multirow[t]{2}{*}{ Total (n) } & \multirow{2}{*}{$\begin{array}{l}\mathrm{P} \\
\text { value }\end{array}$} \\
\hline & No (\%) & Yes (\%) & & \\
\hline Neutral & $988(69.2)$ & $439(30.8)$ & 1427 & \\
\hline \multicolumn{4}{|c|}{ I'm against children vaccine as long-term side effects of the vaccine aren't known } & $\hat{0.001}$ \\
\hline No & $411(52.6)$ & $370(47.4)$ & 781 & \\
\hline Yes & $1407(78.0)$ & $397(22.0)$ & 1804 & \\
\hline Neutral & $732(63.2)$ & $427(36.8)$ & 1159 & \\
\hline \multicolumn{4}{|c|}{ Children should be vaccinated against COVID- 19 only when advised by a physician } & $\begin{array}{l}< \\
0.001\end{array}$ \\
\hline No & $851(81.4)$ & $195(18.6)$ & 1046 & \\
\hline Yes & $969(58.2)$ & $696(41.8)$ & 1665 & \\
\hline Neutral & $730(70.7)$ & $303(29.3)$ & 1033 & \\
\hline \multicolumn{4}{|c|}{ The government have the right to impose COVID-19 vaccine on all citizens } & $\hat{0.001}$ \\
\hline No & $1471(78.3)$ & $408(21.7)$ & 1879 & \\
\hline Yes & $570(55.4)$ & $458(44.6)$ & 1028 & \\
\hline Neutral & $509(60.8)$ & $328(39.2)$ & 837 & \\
\hline \multicolumn{4}{|c|}{ COVID-19 vaccine will end the pandemic } & $\dot{0} 001$ \\
\hline No & $1193(78.7)$ & $322(21.3)$ & 1515 & \\
\hline Yes & $481(54.4)$ & $404(45.6)$ & 885 & \\
\hline Neutral & $876(65.2)$ & $468(34.8)$ & 1344 & \\
\hline \multicolumn{4}{|c|}{ Children should not be vaccinated against COVID-19 because vaccination is painful } & $\hat{0.001}$ \\
\hline No & $1276(62.2)$ & $777(37.8)$ & 2053 & \\
\hline Yes & $536(77.8)$ & $153(22.2)$ & 689 & \\
\hline Neutral & 738 (73.7) & $264(26.3)$ & 1002 & \\
\hline \multicolumn{4}{|c|}{$\begin{array}{l}\text { Children should not be vaccinated against COVID-19 due to lack of scientific research about } \\
\text { effects of the vaccine on children }\end{array}$} & $<.001$ \\
\hline No & $363(52.2)$ & $332(47.8)$ & 695 & \\
\hline Yes & $1568(77.8)$ & $448(22.2)$ & 2016 & \\
\hline
\end{tabular}




\begin{tabular}{|c|c|c|c|c|}
\hline \multirow[t]{2}{*}{ Variable } & \multicolumn{2}{|c|}{ Children vaccination status } & \multirow[t]{2}{*}{ Total (n) } & \multirow{2}{*}{$\begin{array}{l}P \\
\text { value }\end{array}$} \\
\hline & No (\%) & Yes (\%) & & \\
\hline Neutral & $619(59.9)$ & $414(40.1)$ & 1033 & \\
\hline \multicolumn{4}{|c|}{ COVID-19 vaccine is not effective because of the frequent mutations of the virus } & $\hat{0}_{0.001}$ \\
\hline No & $525(57.5)$ & $388(42.5)$ & 913 & \\
\hline Yes & $1131(78.5)$ & $309(21.5)$ & 1440 & \\
\hline Neutral & $894(64.3)$ & $497(35.7)$ & 1391 & \\
\hline \multicolumn{4}{|c|}{ COVID-19 vaccine changes human genes } & $\begin{array}{l}<.001 \\
0.001\end{array}$ \\
\hline No & $891(63.0)$ & $523(37.0)$ & 1414 & \\
\hline Yes & $472(77.8)$ & $135(22.2)$ & 607 & \\
\hline Neutral & $1187(68.9)$ & $536(31.1)$ & 1723 & \\
\hline
\end{tabular}

In the binary regression analysis, the vaccination status was categorized into two main levels; (Yes) and (No). Children's vaccination was significantly correlated with parents' age, education, occupation, parents' previous COVID-19 infection, and their vaccination status. Participants aged $\geq 50$ years and those aged 40-50 years had an OR of $18(\mathrm{OR}=17.9, \mathrm{Cl}$ : 11.16-28.97) and $13(\mathrm{OR}=13.2, \mathrm{Cl}: 8.42-20.88)$ for vaccinating their children compared to those aged 18-29 years. Significantly, parents who had COVID-19 vaccine were five folds more likely to vaccinate their children compared with parents who didn't receive the vaccine $(\mathrm{OR}=4.9, \mathrm{Cl}: 3.12-7.70)$. Table 6 presents the results of the binary logistic regression analysis. 
Table 6

Logistic regression analysis of factors associated with increased odds of having vaccinated children

\begin{tabular}{|c|c|c|c|c|}
\hline \multirow[t]{2}{*}{ Variable } & \multirow[t]{2}{*}{ Odds ratio } & \multicolumn{2}{|c|}{ 95\% Confidence interval } & \multirow[t]{2}{*}{$P$ value } \\
\hline & & Lower & Upper & \\
\hline \multicolumn{5}{|l|}{ Participant's age } \\
\hline $18-29$ & Ref * & & & \\
\hline $30-39$ & 2.2 & 1.43 & 3.62 & $<0.001$ \\
\hline $40-40$ & 13.2 & 8.42 & 20.88 & $<0.001$ \\
\hline$\geq 50$ & 17.9 & 11.16 & 28.97 & $<0.001$ \\
\hline \multicolumn{5}{|l|}{ Participant's education } \\
\hline Secondary or less & 2.1 & 1.46 & 2.79 & $<0.001$ \\
\hline$\geq$ Graduate & Ref * & & & \\
\hline \multicolumn{5}{|l|}{ Work or study field } \\
\hline None health-related & 1.3 & 1.06 & 1.52 & 0.009 \\
\hline Health-related & Ref * & & & \\
\hline \multicolumn{5}{|c|}{ If the parent had COVID-19 infection before } \\
\hline No & 1.3 & 1.07 & 1.47 & 0.005 \\
\hline Yes & Ref * & & & \\
\hline \multicolumn{5}{|c|}{ If the parent had COVID-19 vaccine } \\
\hline No & Ref * & & & \\
\hline Yes & 4.9 & 3.12 & 7.70 & $<0.001$ \\
\hline Intend to get the vaccine & 2.7 & 1.49 & 4.94 & 0.001 \\
\hline Don't intend to get the vaccine & 1.8 & 1.01 & 3.35 & 0.044 \\
\hline
\end{tabular}

\section{Discussion}

The first aim of this study was to assess the prevalence of vaccinated children against COVID-19 in eight Arab countries located in the Eastern Mediterranean Region. The results of this study showed that the prevalence of vaccinated children is $31.9 \%$. This preliminary finding is similar to results from a previous study in the Singapore population [23]. Literature about the vaccine coverage amongst children is dearth 
and most published studies have assessed the parents' willingness or intention to vaccinate children rather than true vaccination status. The second aim was to explore parents' attitudes towards vaccinating children against COVID-19 in the Arab countries. The results of this study showed that around one third of the participants (32.5\%) believe that all vaccines are not safe. Despite the majority of the parents (83.0\%) have been already vaccinated against COVID-19, most of them didn't vaccinate their children against COVID-19 and this correlated with many factors as discussed below.

The third aim of this study was to explore factors associated with vaccination and hesitancy of parents towards children's vaccination in several Arab countries. The results of this study showed significant correlations between children's vaccination status and participants' sociodemographic characteristics. For instance, older parents showed extreme higher readiness to vaccinate their children against COVID-19 than younger counterparts. This result is congruent with a previous study which found that parents younger than 40 are more hesitant to vaccinate children [24]. However, this finding mismatches a previous study which showed that parents younger than 35 in Latin American countries are less likely to be hesitant to vaccinate children [25]. In terms of children's number, parents with three or more children were more willing to vaccinate them than their counterparts. Participants of children aged between 12 and 17 years were more ready to vaccinate them than their counterparts. Our findings might be explained by the fact that younger parents usually have younger children (less than 12 years). Despite its approval, vaccination of the children younger than 12 years is still questionable among public.

In terms of gender, fathers showed a higher tendency towards vaccinating their kids than mothers. This result is consistent with a previous study from Lebanon [14] and US [26]. However, the result was different from a previous study in Poland which showed that mothers are more enthusiastic to vaccinate children than fathers [19]. This may be explained by the difference in the social role of fathers or mothers between communities.

Interestingly, parents whose work or study was health-related showed a lower tendency towards vaccinating their children than parents working in non-health-related fields. This result is consistent with a previous study stated that fewer caregivers plan to vaccinate their children against COVID-19 [27]. Also, parents with a lower educational level showed higher readiness towards vaccinating their children than parents with a higher educational level. This finding is consistent with a previous study which showed that undergraduate parents are more enthusiastic to vaccinate children than parents with higher education $[10,25,28]$. This finding is also congruent with previous studies which concluded that parents' educational level is one of the determinants of willingness to vaccinate children $[18,29]$.

Parents who haven't been infected with COVID-19 were more eager to vaccinate their children than other participants. This finding can be explained by their carefulness from being infected with COVID-19. Another explanation to this result may refer to the fear of the vaccine's side effects perceived by those who have already got the infection before as the side effects can be similar to symptoms of the infection itself. This result is supported by previous studies. For example, a study showed that parents who are anxious from COVID-19 are keener to vaccinate children [28]. Another study showed that the perceived 
danger of being infected with COVID-19 is one of the determinants for parents' willingness to vaccinate children [16]. Additionally, another research found that the readiness to get the COVID-19 vaccine increases with a higher perceived susceptibility to COVID-19 [30]. Vaccinated parents and those who intend to get the vaccine in the future were more willing to vaccinate their children than unvaccinated parents and those who do not intend to get the vaccine. The reason behind this difference can be explained by awareness of vaccinated parents about the COVID-19 vaccines which is supported by an earlier study [28].

Results of the current study showed that parents who had received COVID-19 vaccine or those who intend to get the vaccine are more likely to vaccinate their children. These results are consistent with results from another study stated that the likelihood of child vaccination was greater among parents who had already received or were likely to receive a COVID-19 vaccine [31].

Moreover, parents' attitudes towards vaccinating children are significantly associated with their children's vaccination status. For example, almost half of parents who believe that COVID-19 vaccines are safe on children had vaccinated their children. This result is similar to the rates found in a previous scoping review [29]. On the other hand, only one-fifth of parents who don't trust safety of COVID-19 vaccines on children had vaccinated their children.

The results showed that parents who were against children vaccination because of the unknown longterm side effects of the vaccine were less willing to vaccinate their children. This finding matches previous research which found that one of the main parents' concerns is the possible future complications of the vaccine [19]. Similarly, parents who think that the vaccine may change human genes were less eager to vaccinate their children. These findings were consistent with a previous study which showed that vaccination concerns determine parents' willingness to vaccinate children against COVID-19 [23]. These results are consistent with results from Palestine which reported that adequate information about vaccines and their risk-benefit ratios are important to build trust and favorable attitudes towards vaccines [15].

The results of the current study showed also that willingness towards vaccinating children is significantly different depending on the country of residence. For instance, parents from KSA, UAE, Kuwait, and Iraq were more enthusiastic to vaccinate their children than those from Jordan, Lebanon, Palestine, and Qatar. A previous study has shown high rates of vaccine hesitancy in Jordan and Kuwait [32].

\section{Conclusion}

The prevalence of children vaccinated against COVID-19 in Arab countries is not optimal. Moreover, parents in the studied countries are still hesitant to vaccinate their children against the COVID-19. This hesitancy is led by certain parents' socio-demographic characteristics, having COVID-19 infection before, and their vaccination status. To increase COVID-19 vaccination rates in the countries located in the EMR, it is essential to address variables connected to parents' hesitancy to vaccinate children. A probable cause of vaccination hesitancy may be also linked to misleading information shared on media platforms. 
This explanation was addressed in a previous study done on adolescents and parents of adolescents in the USA which showed that social media negatively impacted the opinions of adolescents and parents on COVID-19 vaccination [33].

Face-to-face information or educational interventions should be used to help parents understand why vaccines are important; explain where, how, and when to access service and respond to hesitations and concerns about vaccine safety or effectiveness. Such interventions are interactive and can be tailored to target specific populations or identified barriers. Concise and clear vaccine information should be provided in multiple languages to improve vaccine confidence. Targeted campaigns should be implemented for parents that are socioeconomically disadvantaged and that are less educated.

\section{Abbreviations}

COVID-19: Coronavirus Disease-2019; EMR: Eastern Mediterranean Region; KSA: Kingdom of Saudi Arabia; OR: Odd Ratio; PHEIC: Public Health Emergency of International Concern; UAE: United Arab Emirates.

\section{Declarations}

\section{Ethics approval and consent to participate:}

The protocol of this study was reviewed and approved by Yarmouk University's Institutional Review Board (IRB) Committee (IRB/2021/47). Written Informed consent (electronically) was obtained from all participants. In addition, all the methods were performed conforming to the World Medical Association Declaration of Helsinki. Participation in this study was voluntary. Informed consent was ensured by the presence of an introductory section in the survey used in this study, with the submission of responses implying an agreement to participate.

\section{Consent for publication:}

Not Applicable.

\section{Availability of data and materials:}

The dataset generated and analyzed in this study is not publicly available due to institutional guidelines but is available from the corresponding author on reasonable request.

\section{Competing interests:}

The authors declare that they have no competing interests.

\section{Funding:}


This research project did not receive any specific grant from funding agencies in the public, commercial, or not-for-profit sectors.

\section{Authors' contributions:}

Conceptualization: MK, HK, ABA, WM, AA.; Methodology: MK, HK, ABA, AA; Validation, MK; Formal analysis: MK.; Investigation: all authors; Data curation: all authors; Writing-original draft preparation: MK, HK, ZT.; Writing-review and editing: all authors; Visualization: MK.; Supervision: MK, AA, ABA; Project administration: MK, M-AM. All authors have read and approved to the submitted version of the manuscript.

\section{Acknowledgments:}

We would like to thank all the participants in this survey.

\section{References}

1. Johns Hopkins University Center. COVID-19 Dashboard by the Center for Systems Science and Engineering (CSSE) at Johns Hopkins. 2022. https://coronavirus.jhu.edu/map.html. Accessed on January 12, 2022.

2. Khatatbeh M. The Battle Against COVID-19 in Jordan: From Extreme Victory to Extreme Burden. Front Public Heal. 2021;8.

3. Khatatbeh M, Alhalaiqa F, Khasawneh A, Al-tammemi AB, Khatatbeh $\mathrm{H}$, Alhassoun S, et al. The Experiences of Nurses and Physicians Caring for COVID-19 Patients: Findings from an Exploratory Phenomenological Study in a High Case-Load Country. Int J Environ Res Public Health. 2021;18:117.

4. Khatatbeh M, Khasawneh A, Hussein $\mathrm{H}$, Altahat O, Alhalaiqa F. Psychological Impact of COVID-19 Pandemic Among the General Population in Jordan. Front Psychiatry. 2021;12:618993.

5. Hodgson SH, Mansatta K, Mallett G, Harris V, Emary KRW, Pollard AJ. What defines an efficacious COVID-19 vaccine? A review of the challenges assessing the clinical efficacy of vaccines against SARS-CoV-2. The Lancet Infectious Diseases. 2021;21:e26-35.

6. Al-Tammemi AB, Tarhini Z. Beyond equity: Advocating theory-based health promotion in parallel with COVID-19 mass vaccination campaigns. Public Heal Pract. 2021;2:100142.

7. Neumann-Böhme S, Varghese NE, Sabat I, Barros PP, Brouwer W, van Exel J, et al. Once we have it, will we use it? A European survey on willingness to be vaccinated against COVID-19. European Journal of Health Economics. 2020;21:977-82.

8. MacDonald NE, Eskola J, Liang X, Chaudhuri M, Dube E, Gellin B, et al. Vaccine hesitancy: Definition, scope and determinants. Vaccine. 2015;33:4161-4.

9. Sallam M. Covid-19 vaccine hesitancy worldwide: A concise systematic review of vaccine acceptance rates. Vaccines. 2021;9:160. 
10. Faezi NA, Gholizadeh P, Sanogo M, Oumarou A, Mohamed MN, Cissoko Y, et al. Peoples' attitude toward COVID-19 vaccine, acceptance, and social trust among African and Middle East countries. Heal Promot Perspect. 2021;11:171-8.

11. Hawlader MDH, Rahman ML, Nazir A, Ara T, Haque MMA, Saha S, et al. COVID-19 vaccine acceptance in South Asia: a multi-country study. Int J Infect Dis. 2022;114:1-10.

12. Machida M, Nakamura I, Kojima T, Saito R, Nakaya T, Hanibuchi T, et al. Acceptance of a covid-19 vaccine in japan during the covid-19 pandemic. Vaccines. 2021;9:210.

13. Alduwayghiri EM, Khan N. Acceptance and Attitude toward COVID-19 Vaccination among the Public in Saudi Arabia: A Cross-sectional Study. J Contemp Dent Pract. 2021;22:730-4.

14. Kasrine Al Halabi C, Obeid S, Sacre H, Akel M, Hallit R, Salameh P, et al. Attitudes of Lebanese adults regarding COVID-19 vaccination. BMC Public Health. 2021;21:1-7.

15. Kateeb E, Danadneh M, Pokorná A, Klugarová J, Abdulqader H, Klugar M, et al. Predictors of willingness to receive covid-19 vaccine: Cross-sectional study of palestinian dental students. Vaccines. 2021;9:954.

16. Russo L, Croci I, Campagna I, Pandolfi E, Villani A, Reale A, et al. Intention of Parents to Immunize Children against SARS-CoV-2 in Italy. Vaccines. 2021;9:1469.

17. Smith LE, Amlôt R, Weinman J, Yiend J, Rubin GJ. A systematic review of factors affecting vaccine uptake in young children. Vaccine. 2017;35:6059-69.

18. Voo JYH, Lean QY, Ming LC, Hanafiah NHM, Al-Worafi YM, Ibrahim B. Vaccine knowledge, awareness and hesitancy: A cross sectional survey among parents residing at sandakan district, sabah. Vaccines. 2021;9:1348.

19. Babicki M, Pokorna-Kałwak D, Doniec Z, Mastalerz-Migas A. Attitudes of parents with regard to vaccination of children against covid-19 in Poland. A nationwide online survey. Vaccines. 2021;9:1192.

20. Eberhardt CS, Siegrist CA. Is there a role for childhood vaccination against COVID-19? Pediatric Allergy and Immunology. 2021;32:9-16.

21. Khatatbeh M, Al-Maqableh HO, Albalas S, Al Ajlouni S, A'aqoulah A, Khatatbeh $\mathrm{H}$, et al. Attitudes and Commitment Toward Precautionary Measures Against COVID-19 Amongst the Jordanian Population: A Large-Scale Cross-Sectional Survey. Front Public Heal. 2021;9.

22. Al Momani W, Khatatbeh M, Altaany Z. Antibiotic susceptibility of bacterial pathogens recovered from the hand and mobile phones of university students. GERMS. 2019;9:9-16.

23. Griva K, Tan KYK, Chan FHF, Periakaruppan R, Ong BWL, Soh ASE, et al. Evaluating Rates and Determinants of COVID-19 Vaccine Hesitancy for Adults and Children in the Singapore Population: Strengthening Our Community's Resilience against Threats from Emerging Infections (SOCRATEs) Cohort. Vaccines. 2021;9:1415.

24. Zona S, Partesotti S, Bergomi A, Rosafio C, Antodaro F, Esposito S. Anti-COVID vaccination for adolescents: A survey on determinants of vaccine parental hesitancy. Vaccines. 2021;9:1309. 
25. Urrunaga-Pastor D, Herrera-Añazco P, Uyen-Cateriano A, Toro-Huamanchumo CJ, Rodriguez-Morales AJ, Hernandez A V., et al. Prevalence and factors associated with parents' non-intention to vaccinate their children and adolescents against COVID-19 in Latin America and the Caribbean. Vaccines. 2021;9:1303.

26. Litaker JR, Tamez N, Bray CL, Durkalski W, Taylor R. Sociodemographic Factors Associated with Vaccine Hesitancy in Central Texas Immediately Prior to COVID-19 Vaccine Availability. Int J Environ Res Public Health. 2022;19:368.

27. Goldman RD, Krupik D, Ali S, Mater A, Hall JE, Bone JN, et al. Caregiver willingness to vaccinate their children against COVID-19 after adult vaccine approval. Int J Environ Res Public Health. 2021;18:10224.

28. Bono SA, Siau CS, Chen WS, Low WY, Faria E, Villela DM, et al. Adults ' Acceptance of COVID-19 Vaccine for Children in Selected Lower- and Middle-Income Countries. Vaccines. 2022;10:11.

29. Pan F, Zhao H, Nicholas S, Maitland E, Liu R, Hou Q. Parents' Decisions to Vaccinate Children against COVID-19: A Scoping Review. Vaccines. 2021;9:1476.

30. Patwary MM, Bardhan M, Disha AS, Hasan M, Haque MZ, Sultana R, et al. Determinants of COVID-19 Vaccine Acceptance among the Adult Population of Bangladesh Using the Health Belief Model and the Theory of Planned Behavior Model. Vaccines. 2021;9:1393.

31. Szilagyi PG, Shah MD, Delgado JR, Thomas K, Vizueta N, Cui Y, et al. Parents' intentions and perceptions about COVID-19 vaccination for their children: Results from a national survey. Pediatrics. $2021 ; 148$.

32. Sallam M, Dababseh D, Eid H, Al-Mahzoum K, Al-Haidar A, Taim D, et al. High rates of covid-19 vaccine hesitancy and its association with conspiracy beliefs: A study in jordan and kuwait among other arab countries. Vaccines. 2021;9:42.

33. Middleman AB, Klein J, Quinn J. Vaccine Hesitancy in the Time of COVID-19: Attitudes and Intentions of Teens and Parents Regarding the COVID-19 Vaccine. Vaccines. 2022;10:4.

\section{Figures}




\section{Children's vaccination prevalence per country}

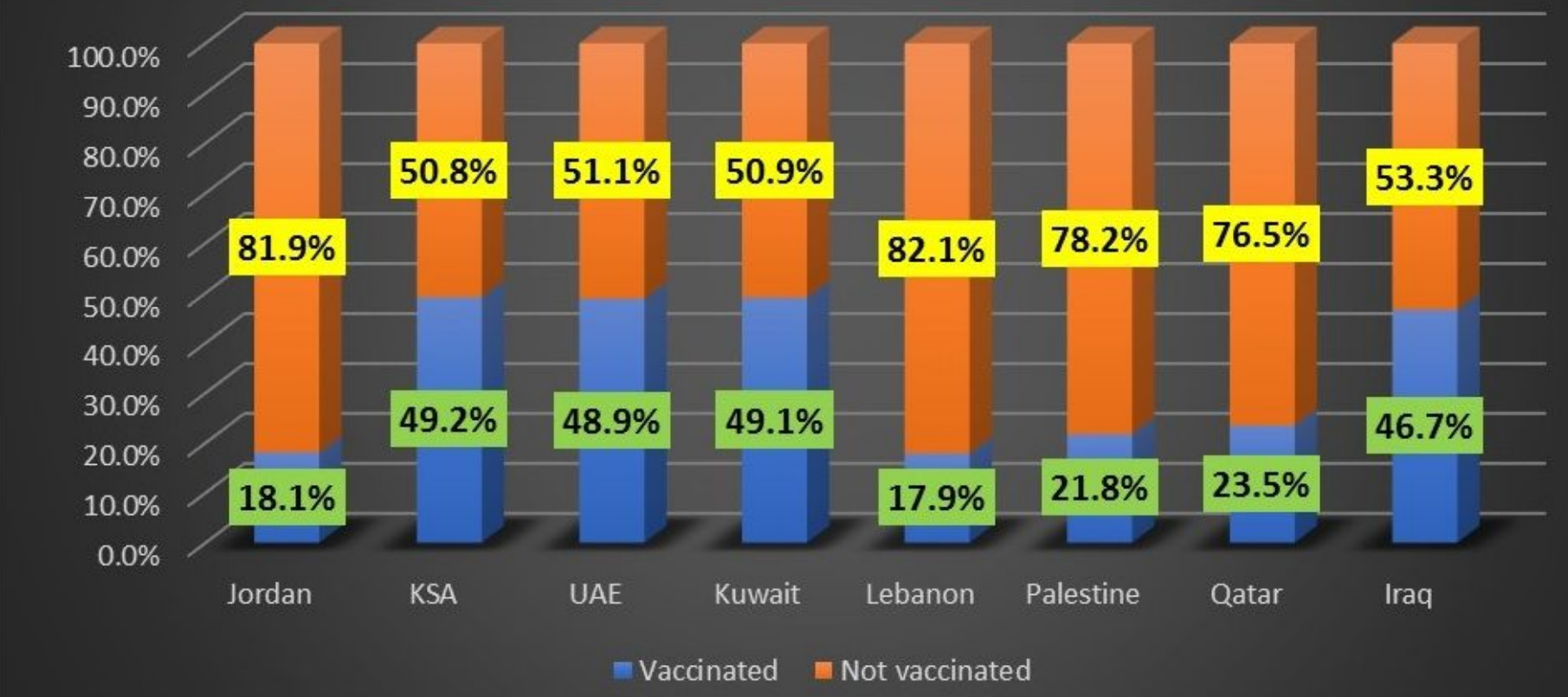

Figure 1

Prevalence of children vaccination against COVID-19 per country. 


\section{Overall prevalence of children's vaccination in eight Arab countries}

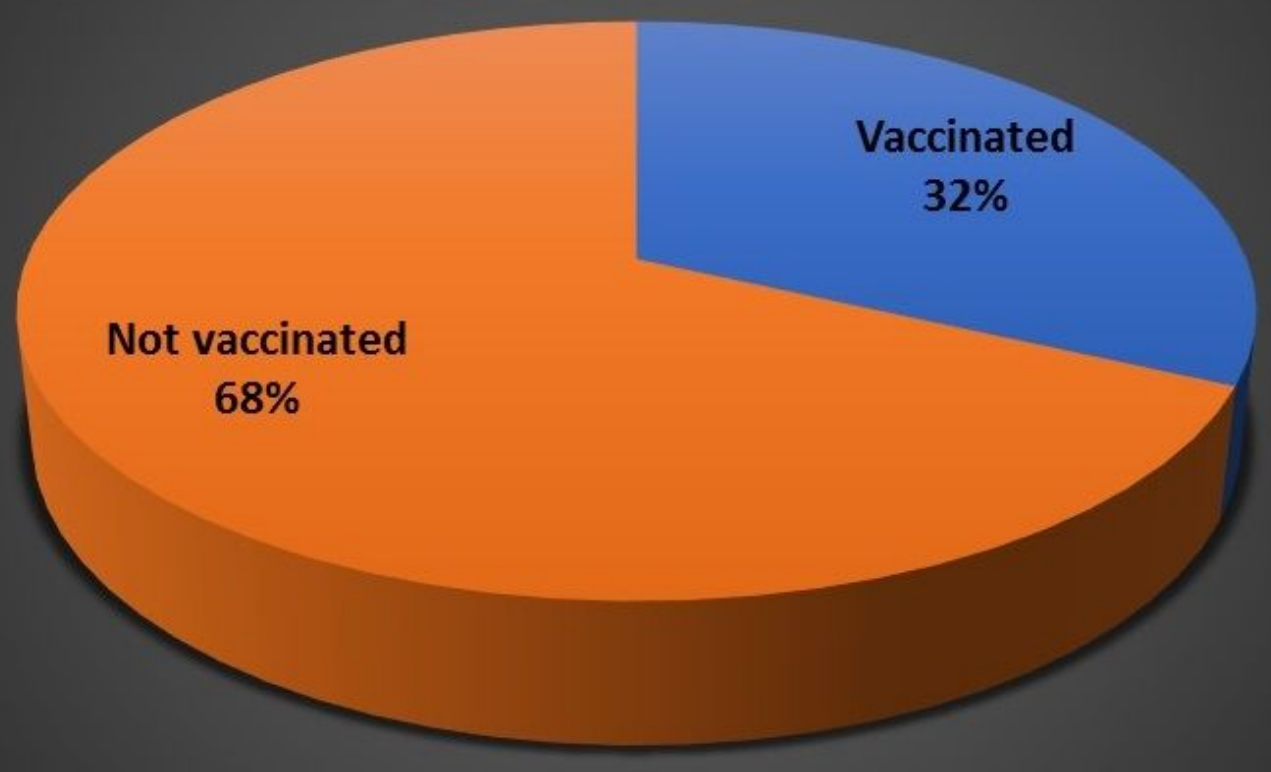

Figure 2

Overall prevalence of children vaccination against COVID-19 in eight Arab countries. 